\title{
New format of the South African Journal of Sports Medicine
}

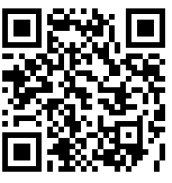

The world of publishing scientific papers is constantly undergoing change. We are aware of this and adapting to meet the changing demands. Instead of publishing four issues each year, we are going to publish the papers as soon as they are accepted for publication after going through peer review. The change has been implemented, so for 2017 there will be one. The number of papers we publish each year will remain the same or increase.

This decision was taken after due consideration. Journals published in paper form are dwindling as they are becoming too expensive to produce. Electronic journals are flourishing. Most of the established credible scientific journals have opted to be published electronically. Some journals produce paper editions and electronic editions simultaneously. These are the wellfunded journals, usually attached to big publishing companies that have the financial and human resources to produce both forms of the journal.

The South African Journal of Sports Medicine, which started in 1982, has undergone change at critical times to meet the changing demands of the publishing industry. The journal was established to represent the South African Sports Medicine Association (SASMA), and was published in-house up until 1998. Then it was published by the Health \& Medical Publishing Group, along with 13 other smaller journals aligned to the health and medical fields. At the end of 2015 the financial model of this publishing company changed and the services offered became unaffordable to SASMA. Coincidently, at the same time the Academy of Science of South Africa (ASSAf) put out feelers about journals wanting to manage themselves through the Open Journal Systems (OJS) they supported. The OJS is a non-profit open source software which can be used to manage and publish journals. This is an alternative to commercial, for-profit online software. This was an attractive proposition for SASMA because ASSAf is a credible organsisation. It is the only national science academy that is officially recognised by the South African government through the ASSAf Act (Act 67 of 2001).

ASSAf's main goal is to provide evidence-based scientific advice on issues of public interest to government and other stakeholders, and promote and apply scientific thinking in the service of society. Therefore supporting journals and enhancing their quality falls within their mandate. ASSAf manages the Scientific Electronic Library Online (SciELO SA; https://www.assaf.org.za). SciELO SA is funded by the South African Department of Science and Technology and endorsed by the South African Department of Higher Education and Training (DHET). SciELO SA is a searchable full-text journal database in service of the South African research community. The database covers a selected collection of peer-reviewed South African scholarly journals and forms an integral part of the SciELO Brazil project (http://www.scielo.br).

The SciELO SA database had 65 journals from different disciplines; the South African Journal of Sports Medicine is included in this list. All SciELO SA journals appear on the Web of Knowledge (WoK) search portal as the SciELO Citation Index and are also found in the DHET List of Approved Journals. The DHET Approved List is compiled annually from international and national journals. These accredited journals included in these lists are taken into account when the government subsidy is granted to universities for scientific publication of research output.

I have explained this as background to the decision we have made about the new format of the journal. Changing the format will not jeopardise our accreditation with the DHET. We are excited because we will be able to improve the quality of the journal with this new structure. Our biggest goal is to reduce the reviewing time of a submitted paper. We also want to reduce the time-fromacceptance to time-to-online-publication. We obviously want to maintain a high standard and publish papers which are meaningful to the field of sport and exercise medicine and allied health sciences. We are confident that we will achieve all these goals with this new

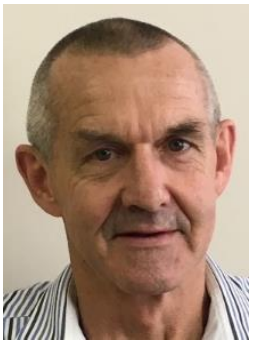
structure.

\section{Mike Lambert}

Editor-in-chief

S Afr J Sports Med 2017;29:1. DOI: 10.17159/2078-516X/2017/v29i0a2856 